\title{
Avaliação do bem-estar de aves poedeiras comerciais: efeitos do sistema de criação e do ambiente bioclimático sobre o desempenho das aves e a qualidade de ovos ${ }^{1}$
}

\section{Sulivan Pereira Alves ${ }^{2}$, Iran José Oliveira da Silva ${ }^{3}$, Sônia Maria de Stefano Piedade ${ }^{4}$}

\author{
${ }^{1}$ Parte da tese do Doutorado da primeira autora. Projeto financiado pela FAPESP. \\ 2 Pós-graduação em Agronomia - ESALQ/USP - Piracicaba - SP - Brasil. \\ ${ }^{3}$ Departamento de Engenharia Rural - NUPEA/ESALQ/USP - Piracicaba - SP - Brasil. \\ ${ }^{4}$ Departamento de Ciências Exatas - ESALQ/USP - Piracicaba - SP - Brasil.
}

RESUMO - Objetivou-se avaliar os efeitos de dois sistemas de criação (gaiolas e cama) no desempenho produtivo e na qualidade de ovos de aves poedeiras. O experimento foi conduzido durante cinco períodos experimentais de 28 dias. Foram utilizadas 64 poedeiras da linhagem Isabrown e 64 da linhagem Hy-line W-36 com 19 e 21 semanas de idade, respectivamente. Avaliou-se a combinação dos dois sistemas de criação (gaiolas convencionais e sistema de criação em cama) e de duas linhagens em um delineamento inteiramente casualizado em arranjo fatorial $2 \times 2$ com quatro repetições. A avaliação térmica foi realizada por meio das temperaturas de bulbo seco e da umidade relativa. Para a avaliação do desempenho produtivo, foram avaliadas a produção de ovos e a conversão alimentar. Na análise da qualidade dos ovos, foram avaliados o peso, a unidade Haugh, a gravidade específica, a espessura, a integridade e a limpeza da casca dos ovos. Não foram observadas diferenças no desempenho produtivo entre sistemas de criação e linhagens. O sistema de criação em cama, quando devidamente projetado, pode ser compatível ao de criação em gaiolas quanto ao desempenho produtivo e à qualidade de ovos produzidos. Além disso, quando em condições menos favoráveis ao conforto térmico, esse sistema de criação pode propiciar melhores resultados de qualidade da casca, com menores perdas de ovos, no entanto, pode resultar em maior porcentagem de ovos sujos, principalmente para a linhagem semipesada.

Palavras-chave: avicultura de postura, conforto térmico, criação em cama

\section{Laying hens welfare evaluation: effects of rearing system and bioclimatic environment on performance and egg quality}

\begin{abstract}
This work aimed to evaluate the effect of two different rearing systems (cages and litter) on productive performance and egg quality of laying hens. The trial was conducted for five experimental periods of 28 days each. Sixty four pullets of the laying strain Isabrown and 64 pullets of the laying strain Hy-Line W-36, with ages of 19 and 21 weeks, respectively, were used. The combination of two rearing systems (conventional cages and floor system with litter) and two layer strains was evaluated using a completely randomized design, with a $2 \times 2$ factorial arrangement, and four replicates. The thermal evaluation was performed by analysis of dry air and black globe temperature and relative humidity. For the productive performance analysis, egg production and feed conversion ratio were evaluated. For the egg quality analysis, egg weight, Haugh unit, specific gravity, integrity, clearness and shell thickness were evaluated. No differences on the productive performance between rearing systems were observed. The floor system, when properly projected, can be comparable to the cage system with respect to the productive performance and the egg quality. Moreover, this rearing system could provided better results for egg quality with lesser egg losses although in less favorable thermal comfort conditions. However, mainly for the semi heavy strain, it could result in larger dirty egg percentage.
\end{abstract}

Key Words: egg production, litter rearing system, thermal comfort

\section{Introdução}

O bem-estar é um dos assuntos mais discutidos atualmente na produção animal. É crescente a convicção dos consumidores de que os animais utilizados para produção de alimentos devem ser bem tratados. As campanhas movidas por diferentes segmentos e a pressão de um número crescente de organizações não-governamentais sensibilizaram a opinião pública em muitos países (principalmente os desenvolvidos) para esse aspecto, o que originou progressos legislativos consideráveis. 
Desse modo, o sistema de criação em gaiolas tornou-se uma das maiores polêmicas acerca do bem-estar animal. O reduzido espaço oferecido e a ausência de caracteres de enriquecimento ambiental impossibilitam ou limitam o repertório de atividades consideradas importantes para o animal. Além disso, as práticas empregadas (elevada densidade, a muda forçada e a debicagem) são questionadas.

De acordo com Hunton (1995) e Tauson (2005), com exceção de poucos países onde existe legislação que proíbe o uso de gaiolas, estas instalações constituem o sistema predominante de criação de aves poedeiras. Na União Européia, as gaiolas serão permitidas somente até o ano de 2012 (Diretiva 1999/74/CE), o que força a adoção de sistemas alternativos para a produção de ovos.

Assim, vários estudos com vistas à medição científica do bem-estar dos animais têm sido realizados, tanto por razões de ordem ética como pelo reconhecimento dos custos mais elevados que essas mudanças implicam para produtores e consumidores. Análises de parâmetros produtivos e da qualidade dos ovos são exemplos de algumas medidas adotadas para determinação dos efeitos do ambiente de criação sobre o desempenho e o bem-estar das aves.

Este trabalho foi realizado com os objetivos de comparar o desempenho produtivo de aves poedeiras leves e semipesadas nos sistemas de criação em cama ao desempenho obtido em sistema de criação em gaiolas e identificar os efeitos desses sistemas de criação sobre a produção e a qualidade dos ovos.

\section{Material e Métodos}

O experimento foi desenvolvido na Escola Superior de Agricultura Luiz de Queiroz (ESALQ/USP), em Piracicaba, SP, localizada a $22^{\circ} 42^{\prime} 30^{\prime}$ ' de latitude, $47^{\circ} 38^{\prime} 00^{\prime \prime}$ de longitude e $546 \mathrm{~m}$ de altitude. O clima da região, de acordo com a classificação de Koppen, é Cwa (subtropical). O experimento constou de cinco períodos experimentais de 28 dias. Foram utilizadas 64 poedeiras da linhagem Hy-Line W36 com 22 semanas de idade e peso vivo de 1,4 \pm 0,09 e 64 poedeiras da linhagem Isabrown com 19 semanas de idade e 1,7 $\pm 0,12$ de peso vivo. Adotou-se o delineamento inteiramente casualizado (DIC), em arranjo fatorial $2 \times 2$, composto de dois sistemas de criação (gaiola e cama) e duas linhagens (Hy-Line W-36 e Isabrown), totalizando quatro tratamentos, cada um com quatro repetições. No sistema de criação em gaiolas, foram utilizadas gaiolas de arame galvanizado com três compartimentos de 0,33×0,40 ×0,40 cm. Em cada compartimento, foram alojadas três aves, totalizando nove aves por gaiola, em um espaço de $440 \mathrm{~cm}^{2}$ por ave para ambas as linhagens. As gaiolas dispunham de bebedouro tipo nipple e comedouro tipo calha em chapa galvanizada. Para o sistema de criação em cama, foram construídos boxes experimentais em madeira e tela, com $1 \mathrm{~m}^{2}$ de área livre, com densidade de 7 aves $/ \mathrm{m}^{2}\left(1.428 \mathrm{~cm}^{2} /\right.$ ave). Cada boxe dispunha de um ninho para atender às sete aves alojadas, de acordo com normas da União Européia (CCE, 1999), comedouro tipo calha e bebedouro tipo nipple.

A temperatura e a umidade relativa do ar no interior do aviário foram monitoradas durante todo o período experimental. Os registros das variáveis meteorológicas foram realizados a cada 15 minutos por meio de sensores conectados a um minidatalogger localizado no interior da instalação, a $0,5 \mathrm{~m}$ de altura do piso, representando o microclima do local.

Diariamente, foi registrado o número de ovos de cada parcela experimental, incluindo os trincados, quebrados e anormais. A produção média foi obtida por meio da relação entre o número de ovos produzidos e o número de aves da parcela (produção na base ave/dia). Ao final de cada semana, foi calculada a produção média, em porcentagem.

O peso médio dos ovos foi calculado pela divisão da massa total de ovos de cada parcela pelo número de ovos produzidos no dia e o resultado foi expresso em gramas. O consumo médio de ração foi obtido pela diferença entre a quantidade de ração fornecida e a consumida. A conversão alimentar foi avaliada por meio da relação entre a quantidade de alimento consumido (kg) e a produção semanal de ovos (em dúzia).

Para observação da integridade da casca, diariamente, os ovos foram avaliados por ovoscopia para determinação do número de ovos íntegros, trincados ou quebrados e avaliação da limpeza, pela qual foram classificados em limpos, pouco sujos e sujos (ESTADOS UNIDOS, 2000). No caso dos ovos das aves alojadas em cama, foram registrados os locais de postura (ninho ou piso). Durante cada período experimental, foram realizadas análises de gravidade específica, espessura da casca e unidades Haugh.

As variáveis foram analisadas por meio da análise de variância e as médias, comparadas pelo teste Tukey, a 5\% de probabilidade.

\section{Resultados e Discussão}

Na Figura 1 são representadas as variações de temperatura e os limites críticos inferior (LCI) e superior (LCS) de temperaturas recomendados para aves, segundo os manuais de criação. 


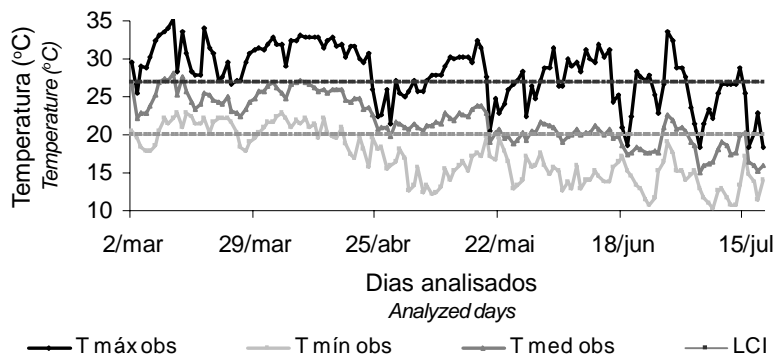

Figura 1 - Limites de temperatura crítica inferior (LCI) e superior (LCS) para as linhagens Hy Line W-36 e Isabrown e médias de temperatura do ar no interior do aviário. Temp max obs = temperatura máxima observada; T mín obs = temperatura mínima observada; T méd obs = temperatura média observada; $\mathrm{LCI}=$ limite crítico inferior; LCS = limite crítico superior.

Figure 1 - Low and upper critical limits of temperature for the strains $\mathrm{Hy}$ Line $W-36$ and Isabrown and the average of temperatures in the aviary. Temp max obs = maximal temperature observed; Minimal temperature observed; T méd obs = average temperature observed, $L C I=L o w$ critical limit; $L C S=$ upper critical limit.

No primeiro e segundo períodos experimentais, houve tendência de temperatura média mais elevada e com menor amplitude térmica. Por outro lado, no 3ํㅜ , 4ํㅡ e $5^{\circ}$ períodos experimentais, foram encontrados menores valores de temperatura média, porém, com ocorrência de maior amplitude térmica, com variações de até $17^{\circ} \mathrm{C}$ entre a temperatura mínima e a máxima no 4으 e 5으 períodos.

Segundo Freeman (1988), a faixa de termoneutralidade para poedeiras situa-se entre 21 e $28^{\circ} \mathrm{C}$. De acordo com o Guia de Manejo Hy Line W-36 (2002), a temperatura ambiente e a umidade relativa ótimas devem variar de 21 a $27^{\circ} \mathrm{C}$ e de 40 a $60 \%$, respectivamente. Para as aves Isabrown, esses valores situam-se entre 20 e $27^{\circ} \mathrm{C}$ e entre 65 e $75 \%$, sendo recomendados valores entre 23 e $24^{\circ} \mathrm{C}$ durante a fase de postura (Guia de manejo Isabrown, 2002).

Apesar de os valores de temperatura média observados durante o experimento terem situado dentro dos limites críticos estabelecidos na literatura e nos manuais dessas linhagens, os valores de temperatura máxima ultrapassaram os limites críticos superiores em praticamente todos os dias dos períodos analisados.

Resultados de vários estudos indicam os efeitos do estresse por calor e das variações sazonais e diárias de temperatura e umidade relativa sobre o desempenho produtivo das aves e a qualidade dos ovos (Daniel \& Balnave, 1981; Mahmoud et al., 1996; Mashaly, 2004). Sabe-se que, sob estresse por calor, a ave pode apresentar perda de peso corporal (Scott \& Balnave, 1988), diminuição na produção (Muiruri \& Harrison, 1991), no peso dos (Balnave \&
Muheereza, 1997) e na qualidade de casca (Emery et al., 1984), geralmente acompanhado de decréscimo no consumo alimentar. De acordo com Mahmoud (1996), o estresse por calor provoca alterações no balanço ácido-base e diminuição da habilidade das células do duodeno no transporte de cálcio, que podem ser fatores críticos para a produção e as características da casca do ovo. Além disso, as reduções da produção nos períodos quentes podem estar relacionadas à diminuição no consumo alimentar (Daniel \& Balnave, 1981).

Não houve diferenças produtivas entre sistemas de criação, pois as produções de ovos em gaiola e em cama foram equivalentes (Tabela 1), o que está de acordo com as observações de Abrahamsson \& Tauson (1995), Tanaka \& Hurnik (1992) e Mench et al. (1985).

Do mesmo modo, a conversão alimentar não diferiu entre os sistemas de criação (Tabela 1). As diferenças nos valores de conversão alimentar entre linhagens podem ser atribuídas às características intrínsecas das linhagens, pois uma era leve (Hy-Line W-36) e a outra semipesada (Isabrown). De acordo com North \& Bell (1990), além da linhagem, fatores como a idade ao início da postura, o peso corporal, a uniformidade, a nutrição, a sanidade e o manejo aplicado estão amplamente envolvidos na eficiência de produção de um lote. Contudo, a manutenção e o controle desses fatores dependem das condições do ambiente físico ao qual a ave está submetida.

Apesar de a avaliação do período experimental total não ter apresentado diferenças produtivas entre os sistemas de criação (Tabela 2), no $2^{\circ}$ período, para as aves Hy-Line W-36, e no 3o período, para as aves Isabrown, a produção de ovos diferiu significativamente $(\mathrm{P}<0,05)$ entre os sistemas de produção.

Os sistemas de criação não influenciaram $(\mathrm{P}>0,05)$ a conversão alimentar em nenhum dos períodos avaliados, diferentemente do constatado por Moster et al. (1995).

No 1 o período experimental, o coeficiente de variação para a conversão alimentar foi elevado, em decorrência da desuniformidade na entrada em postura, principalmente nas aves do sistema em cama, provavelmente em virtude das diferenças de maturidade sexual. O pico de postura das aves da linhagem Hy-Line W-36 em gaiola (Tabela 2) ocorreu no $2^{\underline{0}}$ período experimental e o das aves em cama, no 5 oㅡ período. Para as aves da linhagem Isabrown, o pico de postura ocorreu no mesmo período em ambos os sistemas de criação, porém, o declínio da produção após o pico foi menos acentuado para as aves em gaiola. Uma possível explicação foi o fato de que estas aves se encontravam mais próximas dos pontos de luz e recebiam estímulos luminosos mais 
Tabela 1 - Produção de ovos e conversão alimentar nos sistema de criação no período experimental total Table 1 - Egg production and feed conversion in the housing systems in the total experimental period

\begin{tabular}{|c|c|c|c|c|c|c|}
\hline \multirow[t]{2}{*}{$\begin{array}{l}\text { Linhagem } \\
\text { Strain }\end{array}$} & \multicolumn{2}{|c|}{$\begin{array}{l}\text { Produção de ovos }(\% / \text { ave/dia }) \\
\text { Egg laying percentage }(\% / \text { hen/day) }\end{array}$} & \multirow[t]{2}{*}{ CV (\%) } & \multicolumn{2}{|c|}{$\begin{array}{c}\text { Conversão alimentar (kg ração/dúzia ovos) } \\
\text { Feed conversion( } \mathrm{kg} \text { ration/dz egg) }\end{array}$} & \multirow[t]{2}{*}{ CV (\%) } \\
\hline & $\begin{array}{l}\text { Gaiola } \\
\text { Cage }\end{array}$ & $\begin{array}{l}\text { Cama } \\
\text { Litter }\end{array}$ & & $\begin{array}{l}\text { Gaiola } \\
\text { Cage }\end{array}$ & $\begin{array}{l}\text { Cama } \\
\text { Litter }\end{array}$ & \\
\hline $\begin{array}{l}\text { Hy-Line W-36 } \\
\text { Isabrown }\end{array}$ & $\begin{array}{l}86,92 \mathrm{aA} \\
87,79 \mathrm{aA}\end{array}$ & $\begin{array}{l}85,86 \mathrm{aA} \\
86,55 \mathrm{aA}\end{array}$ & 17,62 & $\begin{array}{l}1,33 \mathrm{aA} \\
1,56 \mathrm{aB}\end{array}$ & $\begin{array}{l}1,38 \mathrm{aA} \\
1,57 \mathrm{aB}\end{array}$ & 14,17 \\
\hline
\end{tabular}

Médias seguidas de mesma letra minúscula na mesma linha e maiúscula na mesma coluna não diferem $(P>0,05)$ pelo teste Tukey. Means followed by the same small letters within a row and capital letter within a column do not differ $(P>0.05)$ byTukey test.

Tabela 2 - Produção de ovos e conversão alimentar nos sistemas de criação em cada período experimental Table 2 - $\quad$ Egg production and feed conversion in the housing systems in each experimental period

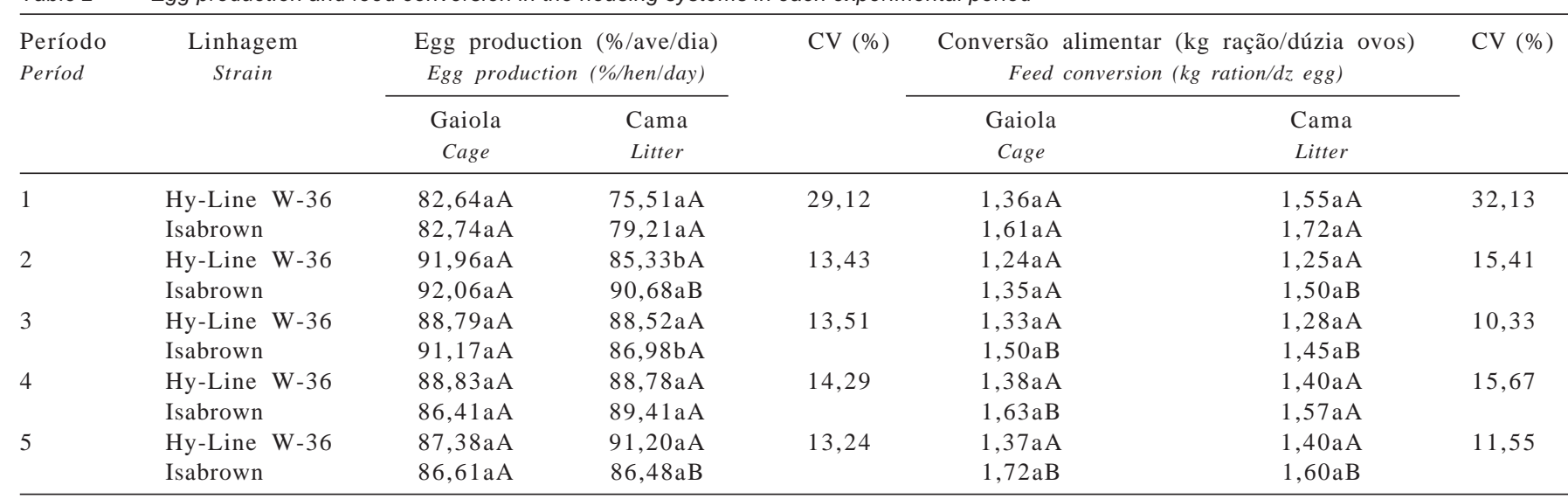

Médias seguidas de mesma letra minúscula na mesma linha e maiúscula na mesma coluna não diferem pelo teste Tukey (P>0,05).

Means followed by the same small letters within a row and capital letter within a column do not differ (P>0.05) byTukey test.

intensos, com efeitos na taxa de ovulação. Além disso, as pequenas diferenças de peso vivo também podem ter favorecido a maturidade sexual mais avançada das aves em gaiola.

De modo geral, não houve diferenças para as características de peso e unidade Haugh entre sistemas de criação (Tabela 3), o que está de acordo com os resultados reportados por Mench et al. (1985). Os pesos dos ovos diferiram, em virtude das características intrínsecas das linhagens, apenas no $2^{\circ}$ período, para a linhagem Hy-Line W-36, e no 5 - período, para as aves Isabrown.

Na análise da espessura da casca (Tabela 4), nos períodos de maior estresse por calor ( $2^{\underline{0}}$ e $3^{3}$ o períodos), os ovos apresentaram casca mais fina, principalmente aqueles provenientes das aves em gaiolas, o que ocasionou diferenças significativas entre sistemas de criação. No $2^{2}$ o período experimental, houve efeito da interação sistema de criação $x$ temperatura ambiente sobre a espessura de casca dos ovos; as aves Isabrown em gaiolas apresentaram espessura inferior à das aves Hy-Line W-36, diferentemente dos demais períodos experimentais, quando a temperatura se manteve dentro da zona de conforto. As aves da linhagem Isabrown parecem ter sofrido mais as conseqüências do estresse por calor, pois apresentaram reflexos na qualidade da casca dos ovos, o que, segundo Barbosa Filho (2006), está relacionado ao seu maior porte e, conseqüentemente, à sua maior intolerância às temperaturas elevadas.

Uma vez que a gravidade específica constitui uma medida complementar da qualidade da casca, as observações para análise desse parâmetro de qualidade foram similares às realizadas para avaliação da espessura da casca.

Ressalta-se que, neste trabalho, ambos os sistemas de criação estavam inseridos no mesmo ambiente e as diferenças nas respostas das aves se devem às características de microclima de cada sistema. O maior estresse por calor sofrido pelas aves em gaiola pode estar relacionado à dificuldade dessas aves em realizar a termorregulação neste ambiente. A ausência de material de cama e de espaço para movimentos que auxiliem na perda de calor são fatores que, somados à maior densidade por área, contribuem para o maior estresse térmico no sistema de criação em gaiolas. Apesar de apresentar como vantagem o maior controle sobre a produção, o consumo de ração e a qualidade dos 
Tabela 3 - Peso dos ovos e unidade Haugh nos sistema de criação em cada período experimental Table 3 - Egg weight and Haugh unit in the housing systems in each experimental period

\begin{tabular}{|c|c|c|c|c|c|c|c|}
\hline \multirow[t]{2}{*}{$\begin{array}{l}\text { Período } \\
\text { Períod }\end{array}$} & \multirow[t]{2}{*}{$\begin{array}{l}\text { Linhagem } \\
\text { Strain }\end{array}$} & \multicolumn{2}{|c|}{$\begin{array}{l}\text { Peso do ovo } \\
\text { Egg weight }\end{array}$} & \multirow[t]{2}{*}{ CV (\%) } & \multicolumn{2}{|c|}{ Unidade Haugh } & \multirow[t]{2}{*}{ CV (\%) } \\
\hline & & $\begin{array}{l}\text { Gaiola } \\
\text { Cage }\end{array}$ & $\begin{array}{l}\text { Cama } \\
\text { Litter }\end{array}$ & & $\begin{array}{l}\text { Gaiola } \\
\text { Cage }\end{array}$ & $\begin{array}{l}\text { Cama } \\
\text { Litter }\end{array}$ & \\
\hline \multirow[t]{2}{*}{1} & Hy-Line W-36 & $54,08 \mathrm{aA}$ & $52,75 \mathrm{aA}$ & \multirow[t]{2}{*}{6,5} & $97,56 \mathrm{aA}$ & 97,80 a A & \multirow[t]{2}{*}{6,9} \\
\hline & Isabrown & $58,96 a \mathrm{~B}$ & $59,21 \mathrm{aB}$ & & $91,80 \mathrm{aB}$ & $89,32 \mathrm{aB}$ & \\
\hline 2 & Hy-Line W-36 & $55,82 \mathrm{aA}$ & $53,23 \mathrm{bA}$ & 7,1 & $94,90 \mathrm{aA}$ & $96,73 a A$ & 7,2 \\
\hline 3 & Isabrown & $64,72 \mathrm{aB}$ & $62,50 \mathrm{aB}$ & 7,2 & $89,86 a \mathrm{~B}$ & $92,00 \mathrm{aB}$ & 6,7 \\
\hline \multirow[t]{2}{*}{4} & Hy-Line W-36 & $61,84 \mathrm{aA}$ & $60,84 \mathrm{aA}$ & \multirow[t]{2}{*}{7,1} & $97,56 \mathrm{aA}$ & $95,61 \mathrm{aA}$ & \multirow[t]{2}{*}{6,3} \\
\hline & Isabrown & $63,04 \mathrm{aB}$ & $62,16 a \mathrm{~B}$ & & $92,65 \mathrm{aB}$ & 88,62 aВ & \\
\hline \multirow[t]{2}{*}{5} & Hy-Line W-36 & $62,29 \mathrm{aA}$ & $60,78 \mathrm{aA}$ & \multirow[t]{2}{*}{7,2} & $89,84 \mathrm{aA}$ & $95,69 \mathrm{aA}$ & \multirow[t]{2}{*}{9,2} \\
\hline & Isabrown & $65,25 \mathrm{aB}$ & $63,22 b B$ & & $85,64 \mathrm{aB}$ & $84,75 a \mathrm{~B}$ & \\
\hline
\end{tabular}

Médias seguidas de mesma letra minúscula na mesma linha e maiúscula na mesma coluna não diferem $(P>0,05)$ pelo teste Tukey.

Means followed by the same small letters within a row and capital letter within a column do not differ $(P>0.05)$ byTukey test.

Tabela 4 - Espessura da casca e gravidade específica nos sistemas de criação em cada período experimental Table 4 - Shell thickness and specific gravity in the housing systems in each experimental period

\begin{tabular}{|c|c|c|c|c|c|c|c|}
\hline \multirow[t]{2}{*}{$\begin{array}{l}\text { Período } \\
\text { Períod }\end{array}$} & \multirow[t]{2}{*}{$\begin{array}{l}\text { Linhagem } \\
\text { Strain }\end{array}$} & \multicolumn{2}{|c|}{$\begin{array}{l}\text { Espessura da casca } \\
\text { Shell thickness }\end{array}$} & \multirow[t]{2}{*}{ CV (\%) } & \multicolumn{2}{|c|}{$\begin{array}{c}\text { Gravidade específica } \\
\text { Specific gravity }\end{array}$} & \multirow[t]{2}{*}{ CV (\%) } \\
\hline & & $\begin{array}{l}\text { Gaiola } \\
\text { Cage }\end{array}$ & $\begin{array}{l}\text { Cama } \\
\text { Litter }\end{array}$ & & $\begin{array}{l}\text { Gaiola } \\
\text { Cage }\end{array}$ & $\begin{array}{l}\text { Cama } \\
\text { Litter }\end{array}$ & \\
\hline \multirow[t]{2}{*}{1} & Hy-Line W-36 & $0,40 \mathrm{aA}$ & $0,41 \mathrm{aA}$ & \multirow[t]{2}{*}{6,2} & $1,087 \mathrm{aA}$ & $1,088 \mathrm{aA}$ & \multirow[t]{2}{*}{0,38} \\
\hline & Isabrown & $0,41 \mathrm{aB}$ & $0,43 \mathrm{aB}$ & & $1,089 \mathrm{aA}$ & $1,090 \mathrm{aA}$ & \\
\hline \multirow[t]{2}{*}{2} & Hy-Line W-36 & $0,34 \mathrm{aA}$ & $0,36 \mathrm{bA}$ & \multirow[t]{2}{*}{9,5} & $1,080 \mathrm{aA}$ & $1,081 \mathrm{aA}$ & \multirow[t]{2}{*}{0,66} \\
\hline & Isabrown & $0,32 \mathrm{aB}$ & $0,37 \mathrm{bA}$ & & $1,076 \mathrm{aA}$ & $1,083 \mathrm{bA}$ & \\
\hline \multirow[t]{2}{*}{3} & Hy-Line W-36 & $0,33 \mathrm{aA}$ & $0,34 \mathrm{bA}$ & \multirow[t]{2}{*}{9,3} & $1,077 \mathrm{aA}$ & $1,082 \mathrm{aA}$ & \multirow[t]{2}{*}{0,85} \\
\hline & Isabrown & $0,34 \mathrm{aA}$ & $0,37 \mathrm{bB}$ & & $1,082 \mathrm{aA}$ & $1,085 \mathrm{aA}$ & \\
\hline \multirow[t]{2}{*}{4} & Hy-Line W-36 & $0,38 \mathrm{aA}$ & $0,38 \mathrm{aA}$ & \multirow[t]{2}{*}{7,9} & $1,084 \mathrm{aA}$ & $1,083 \mathrm{aA}$ & \multirow[t]{2}{*}{0,47} \\
\hline & Isabrown & $0,41 \mathrm{aB}$ & $0,42 \mathrm{aB}$ & & $1,088 \mathrm{aB}$ & 1,089aB & \\
\hline \multirow[t]{2}{*}{5} & Hy-Line W-36 & $0,44 \mathrm{aA}$ & $0,40 \mathrm{aA}$ & \multirow[t]{2}{*}{11,9} & $1,087 \mathrm{aA}$ & $1,085 \mathrm{aA}$ & \multirow[t]{2}{*}{0,30} \\
\hline & Isabrown & $0,44 \mathrm{aA}$ & $0,46 \mathrm{aB}$ & & $1,088 \mathrm{aA}$ & $1,089 a \mathrm{~B}$ & \\
\hline
\end{tabular}

Médias seguidas de mesma letra minúscula na mesma linha e maiúscula na mesma coluna não diferem $(P>0,05)$ pelo teste Tukey.

Means followed by the same small letters within a row and capital letter within a column do not differ $(P>0.05)$ byTukey test.

ovos (Appleby et al., 1992), o sistema de criação em gaiolas mostrou-se mais suscetível aos efeitos das temperaturas, o que contribuiu para alterações da qualidade dos ovos.

Para ambas as linhagens utilizadas no experimento, a maior porcentagem de ovos limpos (Tabela 5) foi obtida no sistema de criação em gaiolas, o que está de acordo com o observado por Pavloski et al. (1981), citado por Mostert et al. (1995). Esses resultados contrariam, no entanto, as observações de Barbosa Filho (2006). Neste estudo, os ovos das aves Isabrown em cama foram os que mais apresentaram sujeiras aderidas, o que pode ser explicado pelo fato de que essas aves, por serem mais pesadas, consomem mais ração e produzem mais fezes e ainda promovem maior compactação da cama, favorecendo retenção de umidade. Essa condição facilitou o acúmulo de sujeira dentro dos ninhos, o que explica a maior proporção de cascas sujas para esta linhagem no sistema de cama. No entanto, entre linhagens no mesmo sistema de criação, não houve diferença significativa para nenhum dos parâmetros analisados, o que indica similaridade entre as linhagens quanto à tendência de apresentar sujeiras na casca dos ovos.

A maior ocorrência de trincas (Tabela 6) ocorreu no sistema de criação em gaiolas para ambas as linhagens. A porcentagem de ovos quebrados, no entanto, não diferiu entre o sistema de criação para as aves Hy-Line W-36. Nas aves da linhagem Isabrown, apesar de não terem sido detectadas diferenças entre as médias, verificou-se ocorrência de maior porcentagem de quebras no sistema de criação em gaiolas. Em uma parcela experimental das aves Isabrown em gaiolas, observou-se, no último período experimental, o vício de bicar e comer ovos, o que contribuiu para a maior porcentagem de ovos quebrados.

De acordo com Appleby et al. (1992), uma das preocupações nos sistemas alternativos às gaiolas é a maior 
Tabela 5 - Porcentagem de ovos limpos, pouco sujos e sujos coletados nos sistemas de criação Table 5 - Percentage of clean, slightly dirty and dirt eggs collected in the housing systems

\begin{tabular}{|c|c|c|c|c|c|c|c|c|c|}
\hline \multirow[t]{2}{*}{$\begin{array}{l}\text { Linhagem } \\
\text { Strain }\end{array}$} & \multicolumn{2}{|c|}{$\begin{array}{c}\text { Limpos }(\%) \\
\text { Clean }\end{array}$} & \multirow[t]{2}{*}{ CV (\%) } & \multicolumn{2}{|c|}{$\begin{array}{c}\text { Pouco sujos (\%) } \\
\text { Slightly dirty }\end{array}$} & \multirow[t]{2}{*}{ CV (\%) } & \multicolumn{2}{|c|}{$\begin{array}{l}\text { Sujos }(\%) \\
\text { Dirty }\end{array}$} & \multirow[t]{2}{*}{ CV (\%) } \\
\hline & $\begin{array}{l}\text { Gaiola } \\
\text { Cage }\end{array}$ & $\begin{array}{l}\text { Cama } \\
\text { Litter }\end{array}$ & & $\begin{array}{l}\text { Gaiola } \\
\text { Cage }\end{array}$ & $\begin{array}{l}\text { Cama } \\
\text { Litter }\end{array}$ & & $\begin{array}{l}\text { Gaiola } \\
\text { Cage }\end{array}$ & $\begin{array}{l}\text { Cama } \\
\text { Litter }\end{array}$ & \\
\hline Hy-Line W-36 & 91,19 aA & $81,35 \mathrm{bB}$ & 5,46 & 5,89aA & $11,65 \mathrm{aA}$ & 27,80 & 2,92aA & 6,99aA & 53,00 \\
\hline Isabrown & $94,18 \mathrm{aA}$ & $81,33 \mathrm{bB}$ & & 2,99aA & 9,73bA & & 2,93aA & 8,92bA & \\
\hline
\end{tabular}

Médias seguidas de mesma letra minúscula na mesma linha e maiúscula na mesma coluna não diferem (P>0,05) pelo teste Tukey.

Means followed by the same small letters within a row and capital letter within a column do not differ $(P>0.05)$ byTukey test.

Tabela 6 - Porcentagem de ovos trincados e quebrados coletados nos sistemas de criação Table 6 - $\quad$ Percentage of cracked and broken eggs collected in the housing systems

\begin{tabular}{|c|c|c|c|c|c|c|}
\hline \multirow[t]{2}{*}{$\begin{array}{l}\text { Linhagem } \\
\text { Strain }\end{array}$} & \multicolumn{2}{|c|}{$\begin{array}{c}\text { Trincado (\%) } \\
\text { Cracked }\end{array}$} & \multirow[t]{2}{*}{ CV (\%) } & \multicolumn{2}{|c|}{$\begin{array}{c}\text { Quebrado (\%) } \\
\text { Brocked }\end{array}$} & \multirow[t]{2}{*}{ CV (\%) } \\
\hline & $\begin{array}{l}\text { Gaiola } \\
\text { Cage }\end{array}$ & $\begin{array}{l}\text { Cama } \\
\text { Litter }\end{array}$ & & $\begin{array}{l}\text { Gaiola } \\
\text { Cage }\end{array}$ & $\begin{array}{l}\text { Cama } \\
\text { Litter }\end{array}$ & \\
\hline $\begin{array}{l}\text { Hy-Line W-36 } \\
\text { Isabrown }\end{array}$ & $\begin{array}{l}2,8 \mathrm{aA} \\
2,03 \mathrm{aA}\end{array}$ & $\begin{array}{l}0,5 \mathrm{bB} \\
0,8 \mathrm{bB}\end{array}$ & 38,91 & $\begin{array}{l}1,51 \mathrm{aA} \\
2,35 \mathrm{aB}\end{array}$ & $\begin{array}{l}1,08 \mathrm{aA} \\
1,42 \mathrm{aA}\end{array}$ & 42,84 \\
\hline
\end{tabular}

Médias seguidas de mesma letra minúscula na mesma linha e maiúscula na mesma coluna não diferem (P>0,05) pelo teste Tukey.

Means followed by the same small letters within a row and capital letter within a column do not differ $(P>0.05)$ byTukey test.

possibilidade de perdas de ovos em decorrência de quebras quando postos fora do ninho. Esse fator é o maior responsável pelas diferenças produtivas entre os sistemas de criação. Além disso, na criação em piso, os ovos tendem a apresentar sujeiras na casca, pois entram em contato com as aves ou com o material de cama do piso ou do ninho se sujando com mais facilidade. Durante as avaliações, raramente observou-se postura em cama, evidenciando a preferência da ave em realizar a postura no ninho. Segundo Appleby et al. (1992), quando os ninhos são semelhantes ao ambiente natural que seria escolhido para a postura, a tendência de a postura ser realizada no chão é menor. Além disso, a maior proporção de ovos trincados ocorreu no sistema de criação em gaiolas, o que pode estar relacionado ao seu maior impacto ao rolar na grade das gaiolas, o que está de acordo com o observado por Barbosa Filho (2006). A menor espessura observada das cascas dos ovos das aves em gaiolas nos períodos de maior estresse por calor pode ter tornado os ovos mais suscetíveis às trincas. Desse modo, o sistema de criação em gaiolas, contrariamente às observações de Mostert et al. (1995) e Appleby et al. (1992), foi o que apresentou maiores perdas por trincas.

\section{Conclusões}

O sistema de criação em cama, quando devidamente projetado, pode ser compatível ao sistema de criação em gaiolas, pois possibilita a obtenção de mesmo desempenho produtivo e qualidade de ovos produzidos em ambas as linhagens utilizadas. Além disso, quando em condições de menor conforto térmico, pode propiciar a qualidade da casca dos ovos e diminuir as perdas de ovos por trincas.

\section{Literatura Citada}

ABRAHAMSSON, P.; TAUSON, R. Performance and cage quality of laying hens in an aviary system. Journal of Applied Poultry Research, n.7, p.225-232, 1998.

APPleby, M.C.; Hughes, B.O.; Elson, H.A. Poultry production systems: behaviour, management and welfare. 2.ed. Wallingford: CAB International, 1992. 238p.

BALNAVE, D.; MUHEEREZA, S.K. Improving eggshell quality at right temperatures with dietary sodium bicarbonate. Poultry Science, n.76, p.558-593, 1997.

BARBOSA FILHO, J.A.D. Egg quality in layers housed in different production systems and submitted to two environmental conditions. Revista Brasileira de Ciência Avícoça, v.8, n.1, p.23-28, 2006.

CONSELHO DAS COMUNIDADES EUROPEIAS. [1999]. Jornal Oficial 203/53. Disponível em <http://europa.eu.int/scadplus/ leg/pt/lvb/l12067.htm.> Acesso em: 2/6/2004.

DANIEL, M.; BALNAVE, D. Response of laying hens to gradual and abrupt increases in ambiente temperature and humidity. Australian Journal of Agricultural Husbandry, v.21, p.189-195, 1981.

EMERY, D.A.; PRAN VOHRA; ERNEST, R.A. The effect of cyclic and constant ambient temperatures on feed consumption, egg production, egg weight and shell thickness of hens. Poultry Science, n.63, p.2027-2035, 1984.

ESTADOS UNIDOS. Department of Agriculture. Egg-grading manual. Washington, 2000. 56p. (Agricultural Handbook, 75).

FREEMAN, B.M. The domestic fowl in biomedical research: physiological effects of the environment. World's Poultry Science Journal, n.44, p.41-60, 1988.

GUIA DE MANEJO HY-LINE. [2002]. Disponível em: <http:// www.hyline.com/w98s_01.pdf.> Acesso em: 2/6/2004. 
GUIA DE MANEJO ISABROWN [2000]. Disponível em http:// www.colaves.com/images/documentos/321ISA\%20CS\%20 Guide\%20ISABrown\%20ESP.pdf. Acesso em: 2/6/2004.

HUNTON, P. Egg production, processing and marketing. In: HUNTON, P. (Ed.). Poultry production. Amsterdam: Elsevier, 1995. p.457-481.

MAHMOUD, K.Z.; BECK, M.M.; SCHEIDELER, S.E. et al. Acute high environmental temperature and calcium-estrogen relationships in the hen. Poultry Science, v.75, p.1555-1562, 1996.

MARSDENSEN, A.; MORRIS, T.R. Quantitative review of the effects of environmental temperature on food intake, egg output and energy balance in laying pullets. British Poultry Science, v.28, p.693-704, 1987.

MASHALY, M.M.; HENDRICS, G.L.; KALAMA, M.A. et al. Effect of heat stress on production parameters and imune response of comercial laying hens. Poultry Science, v.83, p.889-894, 2004.

MOSTERT, B.E.; BOWES, E.H.; van der WALT, J.C. Influence of different housing systems on the performance of hens of four laying strains. South African Journal of Animal Science, v.25, p.80-86, 1995.
NORTH, M.; BELL, D. Comercial chicken production. Manual 4.ed. New York: Van Nostrand Reinold, 1990. 425p.

SCOTT, T.A.; BALNAVE, D. Comparison between concentrated complete diets and self-selection for feeding sexually-maturing pullets at hot and cold temperatures. British Poultry Science, n.29, p.613-625, 1988

TANAKA, T.; HURNIK, J.F. Comparison of behaviour and performance of laying hens housed in battery cages and an aviary. Poultry Science, v.71, p.235-243, 1991.

TAUSON, R. Management and housing systems for layers-efects on welfare and production. World's Poultry Science Journal, v.61, p.477-490, 2005

Recebido: 22/8/2006 